\title{
ENCARCERAMENTO E GÊNERO: UM PANORAMA SOBRE A PENITENCIÁRIA FEMININA DO DISTRITO FEDERAL COMO ESPAÇO EDUCATIVO
}

\author{
Jail and gender: a panorama on the feminine penitentiary of the Federal \\ District as educational space
}

\section{Encarceramiento y género: un panorama sobre la penitenciaria femenina del Distrito Federal como espacio educativo}

RESUMO O texto procura debater as políticas públicas que ofertam no espaço penitenciário a Educação e o acesso à formação profissional como direito da pessoa humana. Ambas um direito assegurado pela Constituição Federal de 1988 - no artigo 205 - bem como, pela Lei de Diretrizes e Bases da Educação (n. 9.394/96). Segundo a Lei de Execução Penal (n. 7.210/84), o trabalho tem a finalidade educativa e produtiva e nesse sentido emerge a Educação de Jovens e Adultos como modalidade constituída a partir do legado e influência direta dos movimentos de cultura e Educação Popular. Entendemos ainda a educação e o trabalho nas prisões sob a perspectiva crítica, humanista, libertária e dialética, devendo ser ressignificado no tempo presente, com vistas a proporcionar a tomada de decisões autônomas e conscientes; que possibilitem a instrumentalização e a emancipação de mulheres e trabalhadoras críticas, uma educação em que o direito ao sonho e à liberdade de pensamento durante o cumprimento de sua pena possibilite uma humanização dessas mulheres, dentro do espaço prisional, repercutindo quando de sua reintegração à sociedade.

PALAVRAS-CHAVE: GÊNERO. EDUCAÇÃ̃ PROFISSIONAL. EdUCAÇÃO EM PRISÕES. EDUCAÇÃO POPULAR. EDUCAÇÃO DE JOVENS E ADULTOS.

ABSTRACT The text seeks to discuss the public policies that offer education in the penitentiary space and access to professional training as a human right. Both are a right guaranteed by the Federal Constitution of 1988 - in article 205 - as well as by the Law of Directives and Bases of Education (n. 9.394/96). According to the Penal Execution Law (n. 7.210/84), the work has the educational and productive purpose and in this sense emerges Youth and Adult Education as a modality constituted from the legacy and direct influence of the movements of culture and Popular Education. We also understand education and prison work from a critical, humanist, libertarian, and dialectical perspective, and must be re-dimensioned in the present time, with a view to providing autonomous and conscious decision-making; that make possible the instrumentalization and emancipation of critical women and

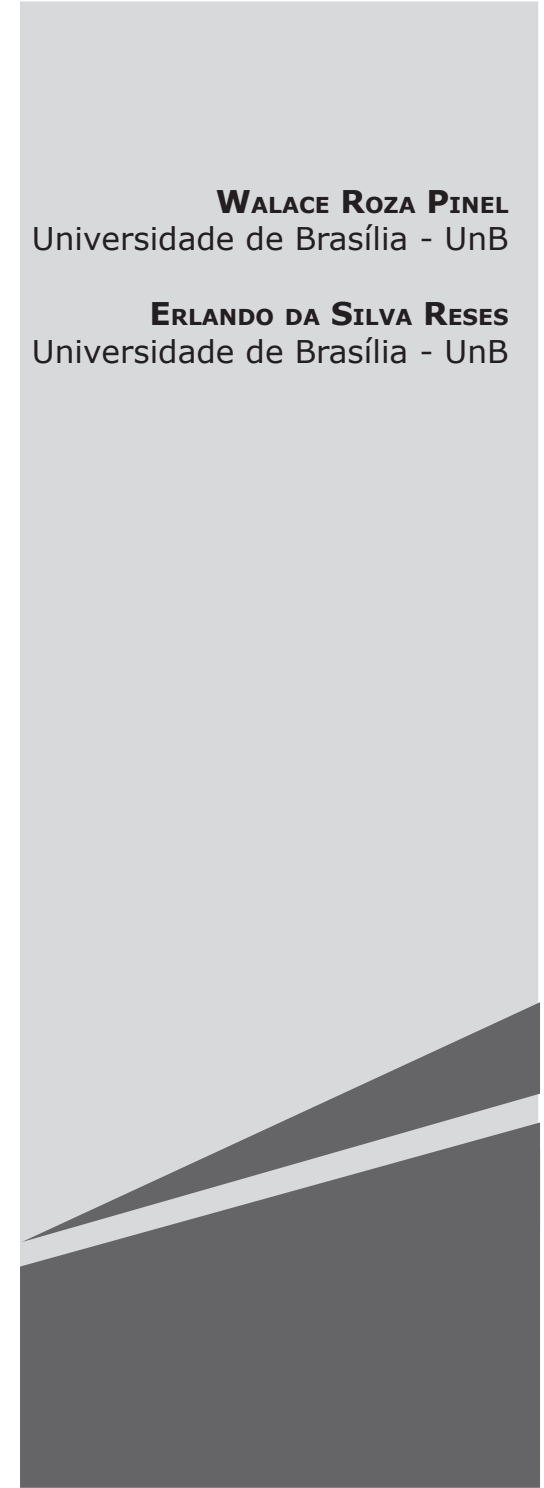


workers, an education where the right to dream and freedom of thought during the fulfillment of their sentence make possible a humanization of these women within the prison space, repercussions when their reintegration into society of the grids.

KEY-WORDS: GENDER. PROFESSIONAL EDUCATION. EDUCATION IN PRISONS. POPULAR EDUCATION. EDUCATION OF YOUTH AND ADULTS.

RESUMEN El texto trata de debatir las políticas públicas que ofrecen en el espacio penitenciario la Educación y el acceso a la formación profesional como derecho de la persona humana. Ambas un derecho asegurado por la Constitución Federal de 1988 - en el artículo 205 - así como por la Ley de Directrices y Bases de la Educación (n. 9.394/96). Según la Ley de Ejecución Penal (n. 7.210/84), el trabajo tiene la finalidad educativa y productiva y en ese sentido emerge la Educación de Jóvenes y Adultos como modalidad constituida a partir del legado e influencia directa de los movimientos de cultura y Educación Popular. Entendemos también la educación y el trabajo en las prisiones bajo la perspectiva crítica, humanista, libertaria y dialéctica, debiendo ser resignificado en el tiempo presente, con miras a proporcionar la toma de decisiones autónomas y conscientes; que posibiliten la instrumentalización y la emancipación de mujeres y trabajadoras críticas, una educación donde el derecho al sueño y la libertad de pensamiento durante el cumplimiento de su pena posibiliten una humanización de estas mujeres, dentro del espacio prisional, repercutiendo cuando su reintegración a la sociedad fuera de las rejas.

PALABRAS CLAVE: Género. EDUCACIÓN PROFESSIONAL. EDUCACIÓN EN PRISIONES. EDUCACIÓN POPULAR. EDUCACIÓN DE JÓVENES Y ADULTOS.

\section{INTRODUÇ̃̃o}

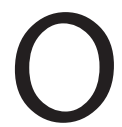

presente artigo procura compreender de forma crítica o fenômeno educativo formal que ocorre dentro do espaço prisional. Para tanto, nos recorremos dos dados empíricos e teóricos colhidos por meio de uma pesquisa de Mestrado em Educação do ano de 2017, em que se verificou as condições de oferta e permanência na educação profissional junto à Penitenciária Feminina do Distrito Federal, doravante PFDF, de acordo. Esclarecemos que Educação e Trabalho no sistema penitenciário brasileiro se tratam ambos de forma não excludente como direitos assegurados pela Constituição Federal de 1988 - no artigo 205 - bem como, pela Lei de Diretrizes e Bases da Educação (n. 9.394/96).
Assim, a oferta da Educação Básica e Trabalho às pessoas em situação de privação de liberdade que desejam prosseguir os estudos "intramuros" é uma inequívoca obrigação do poder público, devendo, a nosso sentir, ser um objeto de maior interesse da área acadêmica e social no país.

Conforme nos aponta o Levantamento Nacional de Informações Penitenciárias (INFOPEN, 2017), em junho/2016 alcançamos a histórica marca de 726.712 pessoas adultas em cumprimento de pena de restrição de liberdade em presídios, delegacias e cadeias públicas. Entretanto, a grande maioria dessa população, 689.510 pessoas, já se encontravam no sistema penitenciário, portanto, aptas ao acesso e permanência às políticas de educação e trabalho voltadas a esse público. 
Em 2016, a população prisional brasileira ultrapassou, pela primeira vez na história a marca de $700 \mathrm{mil}$ pessoas privadas de liberdade, 0 que representa um aumento da ordem de $707 \%$ em relação ao total registrado no início da década de 90 (INFOPEN, p. 9, 2017).

Conforme nos aponta ainda o mesmo referencial teórico, dados sobre a escolaridade da população carcerária refletem a exclusão social e escolar que acompanha populações excluídas historicamente, no seu precário acesso à educação formal. Segundo informação do próprio Ministério da Justiça, quase $80 \%$ da população carcerária não completou sequer o Ensino Médio (INFOPEN, p. 33, 2017). Verticalizando-se a discussão para a questão das mulheres e as políticas públicas voltadas para essa área, trazemos ao debate, sob o ponto de vista teórico-crítico, em que medida as políticas sistemáticas voltadas ao encarceramento de populações possuem determinado alvo seletivo, especialmente para o público feminino.

\section{GÊNERo E SELETIVIDADE PENAL No BRASIL}

Procurando o diálogo a partir do método dialético, concordamos com Handfas (2010), em que muito mais do que uma contextualização histórica, ou do que uma relação do presente com o passado, deve-se levar em conta as formas de articulação sempre contraditórias dos elementos da realidade que se pretende investigar. Entende a autora ainda que a historicização das categorias é a linha de demarcação do marxismo em relação a outras correntes teóricas, sendo uma das categorias centrais do método científico marxista.

Nesse sentido, durante o período colonial, segundo Aguirre (2009, p. 20), as cadeias não eram demasiadamente importantes dentro dos esquemas punitivos idealizados pelas autoridades coloniais, os castigos se aplicavam por meio de outros meios punitivos como: execuções públicas, açoites, trabalhos forçados ou o desterro. No Brasil colonial, não havia separação por sexo nas então cadeias da então Capital Federal ainda no Rio de Janeiro, sendo a condição social a principal classificação que distribuía as apenadas, às mulheres negras, invariavelmente pobres em condições de escravidão, o castigo reservado era o terrível Calabouço, que curiosamente hoje é ocupado fisicamente pelo famoso aeroporto Santos Dumont, porta de entrada da cidade do Rio de Janeiro e cartão-postal do país. ${ }^{1}$

Contava com nove celas distribuídas em três andares, sendo um deles ao nível da rua. Havia ainda as celas femininas e as enfermarias divididas por sexo. Os leitos das enfermarias eram fatais aos doentes. Poucos recuperavam a saúde, quase todos envenenados pelo ar insalubre e pestífero da enfermaria passavam do leito da doença para o leito da morte. Durante mais de quarenta anos, o Aljube serviu de depósito de criminosos, escravos e livres, libertos e militares, homens e mulheres. "Havia confusão de crimes, de idades, de sexos e de condições" (ARAúJO, 2009, p. 115).

Somente em 1850 inaugurou-se a primeira penitenciária da América Latina: a Casa de Correção do Rio de Janeiro, no Brasil, assim como, em outros países da América Latina, entre os quais: Chile (1856), Peru (1862), Equador (1874) e Argentina (1877) ocorre tardiamente e vagarosamente a substituição dos modelos punitivos ao menos oficialmente, dos moldes oficialmente torturantes, introduz-se gradualmente a privação da liberdade como punição. Para o público feminino, apenas durante o Estado Novo oficializou-se a

https://piaui.folha.uol.com.br/materia/nota-sobre-ocalabouco/ Disponível em 26/07/2018. 
prática no Brasil de afastamento físico de homens e mulheres em cumprimento de pena restritiva de liberdade no regime fechado.

Embora o encarceramento de muIheres em salas, celas, alas e seções separadas dos homens fosse uma prática recorrente, até o ano de 1940 não havia qualquer diretriz legal que exigisse ou regulamentasse nem essa prática, nem uma instituição para tal fim específico. Assim, as mulheres presas eram separadas ou não dos homens de acordo com os desígnios das autoridades responsáveis no ato da prisão e de acordo com as condições físicas para tal (ARTUR, 2009).

Nesse contexto, surgem os primeiros equipamentos públicos prisionais destinados exclusivamente à detenção de pessoas do sexo feminino. Primeiramente, em São Paulo, houve a criação do "Presídio de Mulheres", em 1942. No Rio de Janeiro, como parte dessa reorganização, surge a primeira penitenciária exclusivamente feminina em uma capital federal brasileira, a Penitenciária Feminina do Distrito Federal (hoje Penitenciária Talavera Bruce).

A Penitenciária Talavera Bruce começou a ser construída na década de 1930 na região de Bangu, vizinha à Mata de Gericinó, em terreno direcionado pelo Ministério da Justiça para cumprimento de penas das mulheres presas, que até aquele momento cumpriam pena em Ala distinta da masculina, na Penitenciária Central do Distrito Federal. Junto com o Sanatório instalado ao lado, foi inaugurada oficialmente em 09.11.1942, os primeiros estabelecimentos prisionais de Complexo de Bangu, hoje chamado de Complexo de Gericinó (SEAP/RJ, 2016).

Afastada dos presídios para homens àquela época, as mulheres em cumprimento de pena tinham finalmente o amparo legal, ao menos formalmente, que Ihes permitia o cumprimento de suas penas em espaços destinados exclusivamente para esse fim. Inicialmente, sob forte influência eclesiástica, a administração interna do presídio ficou a cargo das Irmãs do Bom Pastor. Entretanto, 13 anos depois de sua inauguração, a administração do espaço é entregue à tutela exclusiva do Estado, mas não dispondo de autonomia administrativa, sendo um apêndice do sistema carcerário masculino.

Apenas em 1966 aquele espaço adquire autonomia administrativa, deixando de pertencer à estrutura administrativa (ainda sob o mesmo espaço físico em estruturas separadas) da Penitenciária Professor Lemos Brito, situado no Complexo Penitenciário de Bangu, e recebeu o nome de Instituto Penal Talavera Bruce. $^{2}$

De modo a buscar um entendimento acerca do hiperencarceramento de mulheres, iniciado sobretudo a partir da década de 70 do século passado, há de se compreender o mercado consumidor mundial de drogas com as políticas repressivas dos Estados Unidos da América, iniciada principalmente após o retorno dos soldados da guerra do Vietnã, que ficou conhecida como "Guerra às Drogas". Os dados demonstram que essa política beligerante aumentou exponencialmente o número de mulheres presas na América Latina, sob o crime do tráfico/cultivo de drogas, sendo essa a principal causa da detenção de mulheres nos países latino-americanos, destacando-se o Brasil na atualidade.

A "guerra às drogas" não é propria-
mente uma guerra contra as drogas.
Não se trata de uma guerra contra
coisas. Como quaisquer outras guer-
ras, é sim uma guerra contra pesso-
as: os produtores, comerciantes e

O presídio foi batizado com o nome do juiz de direito Roberto Talavera Bruce, magistrado atuante no TJRJ na área penal em casos de repercussão. 
consumidores das arbitrariamente selecionadas drogas tornadas ilícitas (KARAM, 2013, p. 4).

De acordo com Gaudad (2015), culturas tradicionais como açúcar, café e algodão foram parcialmente substituídas pela produção de narcóticos, especialmente nos países andinos, destinados ao comércio exterior principalmente Europa e Estados Unidos da América, e posteriormente ao abastecimento interno dos mercados locais emergentes. Assim, proporcionalmente na região, o encarceramento de mulheres deu-se em números maiores que a prisão de homens, e isso ocorreu de forma paradoxal, tendo em vista a maior presença e incorporação de mulheres às economias latinas, assim como, uma expansão do uso e consumo de drogas nesses países.

...o aprisionamento feminino aumentou consideravelmente, tendo, inclusive, ocorrido mais intensamente que o encarceramento masculino em termos proporcionais. É bastante significativo que o crescimento da privação de liberdade das mulheres está profundamente ligado à ampliação da demanda e à oferta de drogas, à criação e modificação de leis sancionadoras das mesmas, bem como à recente presença e atuação de mulheres na produção, na venda e na distribuição destas substâncias criminalizadas (GAUDAD, 2015, p. 11).

Há de se problematizar ainda a contradição histórica no encarceramento de muIheres. Concordamos com Pinel (2015), em que se observa uma ambiguidade no olhar da sociedade sobre a mulher criminosa, atribuindo a culpa masculina seja por abandono, violência ou sedução, a mulher criminalizada é percebida como uma vítima de homens que a exploraram, seduzindo-as para atividades criminosas, o crime não é visto como atividade feminina, negando-se, mesmo no cárcere, a condição de sujeitas autoras de sua história.

Após um necessário debate histórico das condições históricas do cárcere feminino, especialmente na então capital federal, o Rio de Janeiro, entendendo que políticas públicas para o setor implantadas nos grandes centros urbanos especialmente nas capitais impactam todo o país, sendo de alguma forma paradigmáticas, verticalizamos o debate para Brasília e seu “novo” projeto de sistema penitenciário.

\section{A penitenciária feminina do Distrito Federal e o projeto de "REEDUCAÇÃO"}

No campo da sociologia da violência, segundo Adorno (1991), especialmente após a década de 90 do século passado, cresceu nos grandes centros urbanos brasileiros a sensação de insegurança relacionada a partir da percepção do aumento da violência e criminalidade. Nessa linha, se intensificam estudos nas universidades sobre a temática.

Nas terras da chamada "Capital da Esperança”, em 1956 a cidade satélite da Candangolândia inicialmente abrigou os primeiros funcionários com suas famílias, que ergueram as estruturas físicas da nova capital federal, sendo o primeiro acampamento oficial que se tem registro em Brasília.

Em sua engenharia abrigava duas estruturas distintas: de um lado o acampamento-residência dos funcionários de NOVACAP, a igreja, a escola, um restaurante comunitário e o prédio da COBAL. De outro lado ficavam a oficina mecânica, um caixa forte, responsável pelo pagamento dos trabalhadores, uma sede administrativa e o Núcleo de Custódia, destinado ao abrigo dos primeiros sujeitos e sujeitas criminalizados em Brasília (PINEL, p. 65, 2017).

Segundo Carvalho (2003), homens e 
mulheres compartilhavam a mesma estrutura física - situação que paradoxalmente se perpetua até hoje na PFDF - formada por barracões de madeira, estrutura não muito diferente dos operários das obras na capital. Em 1979, deu-se início à desapropriação do terreno destinado à construção da então Penitenciária de Brasília, que ficou conhecida como Papuda, ironicamente graças a uma mulher, pois à época ali morava uma senhora que possuía uma deficiência física, provavelmente o bóCio $^{3}$ (ARAÚJO, 2016) em um afastado rincão da nascente capital federal, sendo conhecida como uma área isolada que ligava Brasília à cidade de Unaí. Assim narrou o Correio Braziliense, à época:

O Ministro da Justiça, Armando Falcão, inaugura hoje as 16:00 horas, a nova penitenciaria de Brasília, na estrada que liga Brasília à cidade mineira de Unaí. Entre as inovações implantadas com a reforma do presídio estão os apartamentos onde os presos poderão receber visitas de seus familiares, música ambiente e celas individuais com banheiros.

Nota-se uma preocupação de ruptura com as antigas práticas penitenciárias praticadas na antiga capital federal e seu sistema penitenciário já centenário, não houve remoção de presos daquelas unidades fluminenses para a nova capital, sendo a nova estrutura penitenciária pensada para abrigar as pessoas que cometiam seus atos delituosos em Brasília, rompendo-se os laços com o Rio de Janeiro e sua antiga Penitenciária deixada aos cuidados do Governo do Estado do Rio de Janeiro.

Era o início da realização de um grande projeto, um modelo de prisão para todo o Brasil, onde os detentos seriam tratados com mais

3 Um aumento do volume da glândula tireoide geralmente causado pela falta de iodo. A existência de nódulos na tireoide também é considerada bócio. dignidade, visando sua reabilitação. Um ambiente jamais visto! Os presidiários se sentiriam mais à vontade para expressar suas ideias e desenvolver habilidades para socialização, mesmo entre os muros da prisão, considerado um lugar deprimente e violento (SILVA, 2012, p. 38).

Em paralelo, havia no Distrito Federal uma unidade correcional destinada ao abrigo de menores infratores na cidade satélite Gama, distante cerca de $30 \mathrm{~km}$ da rodoviária do Plano Piloto, o Centro de Observação para Menores Infratores, conhecido como COLMEIA, conforme observa Carvalho (2002, p. 63):

Trata-se de um espaço que até meados da década de 1990 abrigava crianças e adolescentes em conflito com a Lei e fora desocupado após o advento do Estatuto da Criança e Adolescentes (ECA), quando os antigos alojados foram transferidos para o Centro de Atendimento Juvenil Especializado (CAJE).

Tendo em vista a mudança dos menores, em cumprimento de medidas socioeducativas para o Plano Piloto, o espaço tornou-se ocioso, ocorrendo no ano de 1997 a transferência das mulheres criminalizadas em cumprimento de pena restritiva de liberdade do Presídio Feminino $^{4}$ (PF) - situado no Núcleo de Custódia de Brasília (NCB), dentro do Complexo Penitenciário da Papuda - para o Núcleo de Custódia Feminino de Brasília (NCFB), ficando conhecido desde o início pelo antigo nome COLMÉIA. Observa-se que houve apenas uma transferência das estruturas destinadas ao espaço prisional feminino, não sendo esse complexo construído especificamente para o abrigo de mulheres em cumprimento de pena. A esse respeito analisa Cesar (1996, p. 63):

O histórico do aprisionamento femi-

\footnotetext{
4 Denominação informal do espaço prisional tendo em vista o mesmo nunca ter sido regulamento por essa denominação.
} 
nino no Distrito Federal revela uma situação de constantes improvisos e provisoriedades em relação ao local a ele destinado. Fato que sinaliza a ausência de planejamento de políticas específicas para esta população.

Em 2002 agregou-se a Penitenciária Feminina do Distrito Federal, sob essa denominação, à estrutura da Secretaria de Estado de Segurança Pública, conforme observa CarvaIho (2002), apenas após 14 anos da promulgação da nova Constituição Federal. E 20 anos depois da Lei de Execuções Penais deu-se o devido reconhecimento legal a esse espaço administrado pelo Poder Público.

São indícios suficientes, pois que muito mais do que planejamento e organização, para além do discurso oficial o que se percebe no histórico dos espaços destinados ao cumprimento de pena de mulheres é a repetição de improvisos e decisões não suficientemente debatidas e planejadas, ensejando uma precarização do serviço público ali ofertado. Nesse sentido, trazemos a discussão sobre a oferta de educação e trabalho junto aquele local.

\section{Trabalho E FORMaÇÃo No SISTEMA PENITENCIÁRIO FEMININO DO DISTRITO Federal}

Antes de destacar algumas determinantes que socialmente instituem papéis e funções sociais distintas aos homens e muIheres que acessam a Educação de Jovens e Adultas, precisamos compreender quem são essas mulheres, buscamos, no pensamento de Hobsbawn (2005), inflexões sobre a categoria trabalho na questão de gênero ao longo da história capitalista. Infere o autor acerca da divisão sexual do trabalho que às mulheres desde o início da revolução industrial era reservada uma carga horária maior na dupla jornada fábrica-lar:

...na grande expansão industrial, os processos produtivos reais atenuavam ou mesmo aboliam as diferenças no trabalho entre homens e mulheres, com efeitos de longo alcance nos papéis sociais, sexuais e nas convenções dos sexos (HOBSBAWN, p. 154, 2005).

No sistema penitenciário, para a Lei de Execução Penal (n. 7.210/84), o trabalho tem a finalidade educativa e produtiva. Frise-se a intencionalidade do legislador em estabelecer a precedência do caráter educativo sobre qualquer intencionalidade nas oficinas em presídios e congêneres, embora a Constituição Federal no seu artigo 205 garante a oferta da Educação Básica, sob o aspecto legal o ensino nas instituições prisionais não guardava abrigo na Lei de Diretrizes e Bases da Educação (Lei n. 9.394/96 de 20/10/1996) como modalidade específica de ensino, interpretando-se livremente como categoria de ensino "pertencente" à modalidade da Educação de Jovens e Adultos.

Por meio da Resolução CNE/CEB $\mathrm{n}$. $2 / 2010$, surgem diretrizes nacionais específicas para a educação no regime de privação de liberdade acompanhada do Decreto $\mathrm{n}$. 7.626/2011, que incluiu o plano estratégico de educação no âmbito do Sistema Prisional. Ainda em 2011, acompanhando as políticas que buscavam uma maior articulação entre a criminologia e a garantia de direitos individuais por intermédio do incentivo à Educação de populações em cumprimento de pena, pela Lei n. 12.433/2011 é garantida às pessoas em cumprimento de pena a remissão desta pelo estudo, equiparando-se a educação ao trabaIho, para cada três dias em sala de aula, ou em atividade laboral, há a diminuição em um dia do total da pena. Na mesma linha o Distrito Federal, por meio do Plano Curricular para a Educação Básica (2012), avança no sentido do reconhecimento dessa modalidade de ensino, normatizando sua oferta:

A EJA nas prisões não se limita apenas à escolarização, mas também 
reconhece a educação como direito humano fundamental para a constituição de pessoas autônomas, críticas e ativas frente à realidade que encontram. A oferta da EJA no ambiente prisional significa proporcionar a esses estudantes a instância de construção coletiva que proporciona um convívio da participação social não contemplado em nenhum outro espaço na prisão (BRASIL, p. 13, 2008).

O trabalho e o estudo nas prisões ainda podem ser entendidos como elementos que transformam o "homem violento" em uma peça que executa sua função em perfeita regularidade, tendo por função maior não a formação de uma habilidade útil, mas se constituindo em uma relação de poder, um esquema de submissão individual e de ajustamento a um aparelho de produção (FOUCAULT, 1986). A imprecisão sobre a definição de educação é histórica na organização de instituições prisionais na humanidade ainda. De acordo com Graciano (2008), considera-se educativo historicamente nos presídios tudo aquilo que é pautado por rígidas normas disciplinares.

Nessa linha de raciocínio, a discussão sobre a formação profissional das mulheres em cumprimento de pena que trabalham e estudam nas oficinas profissionais deve compreender sua trajetória sobre diferentes vivências, visto que a questão do sistema prisional feminino no Distrito Federal não pode ser analisad [a] isoladamente ou fora do contexto social. É necessário considerar sua história, seus grupos, seu pertencimento e suas significações (RESES, 2015, p. 13).

$\mathrm{Na}$ Penitenciária Feminina do Distrito Federal (PFDF) conhecida como COLMÉIA, situada na cidade satélite do Gama - DF, a aproximadamente $35 \mathrm{~km}$ do centro da capital, as estudantes contam com um Núcleo de Estudo $(\mathrm{NE})$, onde estão instaladas as salas de aula e as oficinas e a biblioteca, que ofertam, na presente data, os cursos de Enfeites PET, Costura Industrial e Artesanato e eventuais cursos de cabeleireiras. Ainda que não sujeito ao regime da Consolidação das Leis do Trabalho, o trabalho nas oficinas deve ser remunerado, não podendo a remuneração ser inferior a três quartos do salário mínimo. Segundo Gaudad (2015, p. 134):

O fato de participar de alguma oficina profissionalizante ou da escola é visto como um benefício muito positivo pelas presas, porque as ajuda a sobreviver melhor na penitenciária, uma vez que o tempo parece passar mais rápido e se torna menos improdutivo para elas, além de oferecerem a remissão da pena.

Compreendendo a realidade por meio da Teoria das Múltiplas Determinações, entendemos que os cursos oferecidos por meio das oficinas parecem reforçar o estereótipo das profissões subalternizadas reservadas às mulheres das classes trabalhadoras dentro e fora do sistema prisional, cursos que, mesmo quando completados com sucesso, provavelmente não conseguem efetivamente emancipar as portadoras de seu diploma para o mercado de trabalho em posições de destaque ou capacidade técnica notória, sendo, em sua maioria, atividades de pouca complexidade teórica e baixa qualificação técnica reforçando a exclusão social que as acompanha ao longo de suas vidas dentro e fora dos muros.

Nesse sentido, Frigotto (2001) entende que os processos educativos, escolares ou não, constituem-se em práticas sociais mediadoras constituintes da sociedade que subordina o trabalho, os bens da natureza, a ciência e a tecnologia como propriedade privada, valores de troca e a consequente alienação e exclusão de milhões de seres humanos da vida digna ou de sua radical transformação.

\section{ConsideraÇões FINAIS}

Mesmo com a multiplicidade de fatores que ensejam na realidade em dado momento 
histórico, compreendemos que a história nos aponta que não há um projeto político educacional específico contínuo no qual se enseja a implementação de políticas educacionais nos presídios, especialmente no que diz respeito à formação profissional de mulheres no cumprimento de pena restritiva de liberdade em que se propõe sua emancipação social.

A educação profissional passa a ser entendida e fundamentada sob a lógica da empregabilidade, onde cabe o indivíduo se preparar em uma competição pelos empregos disponíveis, não há mais expectativa na nova lógica produtivo-liberal-capitalista do pleno emprego, ao (à) estudante-trabalhador (a) cabe, por meio de diferentes gruas de escolaridade, tornar-se mão de obra disponível às empresas contratantes. Para Saviani (2008), a teoria do capital humano de Schultz aparece agora revisitada sob a forma do neoprodutivismo.

Sob a lógica do capital, especialmente nas sociedades capitalistas periféricas, há de se levar em conta a atual ascensão de políticas do chamado "Estado mínimo", gerando a terceirização às empresas particulares de serviços que, em nossa ótica, deveriam ser conduzidos pelo Estado quando a terceirização se impõe. De acordo com Rangel (2007), os interesses das pessoas em cumprimento de pena caem para o segundo plano nos países da América Latina, que estão desenvolvendo programas educativos centrados principalmente na formação para o trabalho mediante oficinas de produção. Torna-se ainda mais dramático tal cenário para as mulheres, embora menos numerosas, o que poderia representar uma vantagem torna-se uma desvantagem, pois as administrações locais não costumam lhes fornecer cursos específicos em razão do número suposto reduzido de mulheres "interessadas".

...observa-se que os programas educativos desenvolvidos nas prisões enfatizam por demais o desenvolvimento de competências para o trabalho. A princípio, a escolha desse caminho é perfeitamente justificável, a fim de possibilitar aos presos sua reinserção social. Mas a realidade é bem diferente, pois a formação em oficinas, que são, na realidade, muitas vezes, fábricas terceirizadas, demonstrou poucos resultados convincentes no que se refere à formação dos detentos e à sua absorção pelo mundo do trabaIho (RANGEL, 2007, p. 90).

Isto apresenta grande poder de síntese do pensamento crítico ao modelo da "Pedagogia da Exclusão" que, sob a forma tecnicista, busca transformar espaços educativos, onde o trabalho deve possuir em princípio educativo Ireland (2016, p. 63) que ao discutir a prisão como espaço de aprendizagens, parte do pressuposto de que as prisões constituem-se em lócus de múltiplas possibilidades de aprendizagens, construídas no contexto intramuros a partir das experiências que nele vivenciam e que adotam como alternativa para lidar com as privações do encarceramento.

Às mulheres, ainda estigmatizadas e relegadas a um projeto político-carcerário não planejado para recebê-las de forma adequada, são destinadas as "sobras" do sistema. Muito embora a mídia explore ao máximo em seus veículos a prisão de mulheres, como um "espetáculo midiático", a reforma das prisões não está na agenda da sociedade civil brasileira. Segundo Reses (2004, p. 43), os fenômenos que constituem a sociedade têm sua sede na coletividade e não em cada um dos seus membros. É nela que se devem buscar as explicações para os fatos sociais e não nas unidades que a compõem.

Mesmo reconhecendo avanços históricos ao longo do tempo, é tamanha a precariedade das condições carcerárias no Brasil que, mesmo para a Sociedade Civil organizada, ou mesmo órgãos de controle da atuação do Estado - como o Ministério Público - fica relegada a segundo plano a defesa pelo direito à educação e trabalho das mulheres presas.

...as organizações que atuam na defesa dos direitos das pessoas en- 
carceradas, diante de tantas outras demandas e violações no interior da prisão, terminam por atuar na defesa dos direitos civis, relativos à garantia da integridade física e mental daquelas pessoas. Aquelas que se dedicam a reivindicar ensino público de qualidade não incluíram a educação na prisão no seu repertório. Sobre o tema parece haver concordância entre organizações civis e Estadas, não há negação explícita do direito, mas também não há esforços em precisar, no caso da sociedade civil, e viabilizar, por parte do Estado (GRACIANO, 2008, p. 114).

Diante deste quadro dramático, em que, por um lado, a sociedade "conservadora" clama por penas mais severas e, por outro, o cumprimento integral de penas em regime fechado, parece não se importar com direitos básicos fundamentais daquelas condenadas duplamente à pena de prisão e ao estigma social. Cabendo à sociedade civil atuar de forma direta, exigindo por parte do Estado o cumprimento das leis vigentes, especialmente no tocante à oferta obrigatória da Educação Básica, assim como, a oportunidade de aprendizagem profissional que busque melhorar as condições das internas, seja durante o cumprimento da pena seja quando de sua liberdade.

Defendemos que a educação e o trabaIho nas prisões são prerrogativas do Estado, devendo ser analisados e ofertados sob a ótica humanista, ressignificados no tempo presente, que proporcionem a tomada de decisões autônomas e conscientes; que pos- sibilitem a instrumentalização e a emancipação de trabalhadoras críticas. A educação e o trabalho devem procurar manter os sonhos e a liberdade de pensamento enquanto direito fundamental e inalienável da mulher criminalizada, durante o cumprimento de sua pena e quando de sua reintegração à sociedade.

Segundo Cattani e Holzmann (2011, p. 204), a educação profissional deve ser pensada pedagogicamente, de modo a permitir - à mulher afastada temporariamente do convívio social - adquirir e desenvolver conhecimentos teóricos, técnicos e operacionais relacionados à produção de bens e serviços, traduzindo os progressos sociais, pedagógicos e tecnológicos que estão presentes nas atividades humanas que garantem a sobrevivência por meio da transformação da natureza. O exercício do trabalho profissional, ademais de vincular-se a uma atividade produtiva e simbólica, é matizado conforme a esfera em que ele ocorra, seja a esfera doméstica, ou seja do mercado do Estado e da comunidade.

Defende-se neste artigo uma educação profissional integrada à educação básica no espaço da prisão, que entenda o trabalho enquanto princípio educativo, em que as relações sociais entre o trabalho material e intelectual tenham impacto e repercussão na vida social, buscando por meio da integração de múltiplas experiências não apenas de produção fabril subordinada à lógica da terceirização, mas também uma formação humanística e omnilateral que busque contribuir na emancipação das mulheres durante o cumprimento de pena sendo um espaço de reflexão, diálogo e de mediação de conflitos por meio da não violência, assim como quando de seu retorno à sociedade. 


\section{REFERÊNCIAS}

ALMEIDA, Gelson. O Sistema prisional no Rio de Janeiro: Um breve relato sobre o sistema prisional no Rio de Janeiro. s/d. Disponível em: <http://museucarcereuerj.blogspot.com.br/p/ sistema-prisional.html>. Acesso em: 8 jan. 2016.

ARAÚJO, Carlos Eduardo M. de. Entre dois cativeiros escravidão urbana e sistema prisional no Rio de Janeiro 1790-1821. In: MAIA, Clarissa; SÁ NETO, Flávio. História das prisões no Brasil. Rocco: Rio de Janeiro, 2009.

ARTHUR, Ângela. "Presídio de Mulheres": as origens e os primeiros anos de estabelecimento. São Paulo, v. 1950, 1930.

BRASIL. Censo Escolar. Brasília: SEEDF, 2014.

BRASIL. Currículo Em Movimento Da Educação Básica - Educação de jovens e adultos. Brasília: SEEDF, 2014.

BRASIL. Levantamento Nacional de Informações Penitenciárias - INFOPEN. Brasília: Ministério da Justiça, Departamento Penitenciário Nacional, 2014.

BRASIL. Mapa do encarceramento - Os Jovens do Brasil. Secretaria Geral da Presidência da República e Secretaria Nacional de Juventude. Brasília: Presidência da República, 2015.

BRASIL. Plano Distrital de Educação (2015-2024). Brasília: Secretaria de Estado de Educação do Distrito Federal, 2015.

BRASIL. Secretaria de Administração Penitenciária. Complexo de Gericinó. Disponível em: http://www.ri.gov.br/web/seap/principal. Acesso em: 15 jun. 2016.

CARVALHO, Lianne. O Atendimento às mulheres presas na penitenciária feminina do DF: Uma análise do ideário da gestão compartilhada e em rede das políticas públicas sociais na década de 1990. Brasília: Programa de pós-graduação do Departamento de Serviço Social, UnB. Dissertação, 2003, 42-65 p.

CATTANI, Antonio; HOLZMANN, Lorena. Dicionário de trabalho e tecnologia. Editora da UFRGS, 2006.

CESAR, Maria. O Exílio da Vida: o cotidiano de mulheres presidiárias. Brasília: Thesaurus, 1996, $63 \mathrm{p}$.

FOUCAULT, Michel. Vigiar e punir: história da violência nas prisões. Petrópolis: Vozes, 1986.

FRIGOTTO, Gaudêncio. Educação e trabalho: bases para debater a educação profissional emancipadora.

GAUDAD, Ludmila. A tragédia de Maria, o assassinato enquanto experiência constitutiva. Brasília: ICS/UnB, Dissertação Mestrado/UnB, 2008, 334-335 p. 
GAUDAD, Ludmila. MULAS, OLHEIRAS, CHEFAS \& OUTROS TIPOS: Heterogeneidade nas dinâmicas de inserção e permanência de mulheres no tráfico de drogas em Brasília-DF e na Cidade do México. Tese Doutorado/Unb, Brasília, 2015.

GRACIANO, Mariângela. A educação na prisão: hesitações limites e possibilidades. Araraquara, 2008.

HANDFAS, Anna. Uma leitura crítica das pesquisas sobre a relação de trabalho e educação. Brasília: Revista Linhas Críticas, 2010, 140-143 p.

HOBSBAWM, Eric: Pessoas Extraordinárias, Homem e Mulher: imagens da Esquerda. São Paulo: Paz e Terra, 2005.

KARAM, Maria Lucia. Drogas: dos perigos da proibição à necessidade de legalização. Seminário Drogas: dos perigos da proibição à necessidade da legalização. Rio de Janeiro: EMERJ; Instituto Carioca de Criminologia, 2013.

PINEL, Walace. Educação prisional: um olhar sobre as oficinas profissionalizantes na penitenciária feminina do Distrito Federal, Brasília, 2015.

RANGEL, Hugo. Estratégias sociais e educação prisional na Europa: visão de conjunto e reflexões. Revista Brasileira de Educação, v. 12, n. 34, p. 90, 2007.

RESES, Erlando. De vocação para profissão, sindicalismo docente da educação básica no Brasil. Ed. Paralelo 15, 2015. RESES, Erlando. Estudo das representações sociais dos alunos da rede pública do Distrito Federal sobre a sociologia. Dissertação de Mestrado UNB, Brasília, 2004.

RESES, Erlando; PINEL, Walace. Educação de Jovens e Adultos na Penitenciária Feminina do Distrito Federal: possibilidade de pesquisa através do materialismo histórico-dialético. Revista Com Censo, Brasília, 2. ed. esp., n. 5, p. 74-78, 2016.

SAVIANNI, Dermeval. Sobre a natureza e especificidade da educação. Campinas: Autores Associados, 2008.

SEAP. Complexo de Gericinó. Disponível em: http://www.rj.gov.br//web/seap/principal. Acesso em: 15 jun. 2016.

Submetido em: 27-3-2018

Aceito em: 26-7-2018 